\title{
EXAFS analysis of uranium(IV) and thorium(IV) complexes in concentrated $\mathrm{CaCl}_{2}$ solutions
}

\author{
By A. Uehara ${ }^{1, *}$, T. Fujii ${ }^{1}$, H. Matsuura ${ }^{2}$, N. Sato ${ }^{3}$, T. Nagai ${ }^{4}$, K. Minato ${ }^{5}$, H. Yamana ${ }^{1}$ and Y. Okamoto ${ }^{6}$ \\ ${ }^{1}$ Research Reactor Institute, Kyoto University, Asashironishi, Kumatori, Osaka 590-0494, Japan \\ 2 Research Laboratory for Nuclear Reactors, Tokyo Institute of Technology, Ookayama, Meguro, Tokyo 152-8550, Japan \\ ${ }^{3}$ Institute of Multidisciplinary Research for Advanced Materials, Tohoku University, Katahira, Aoba, Sendai, Miyagi, 980-8577, Japan \\ ${ }^{4}$ Nuclear Fuel Cycle Engineering Laboratory, Japan Atomic Energy Agency, Tokai, Ibaraki 319-1194, Japan \\ 5 Nuclear Science and Engineering Directorate, Japan Atomic Energy Agency, Tokai, Ibaraki 319-1195, Japan \\ ${ }^{6}$ Quantum Beam Science Directorate, Japan Atomic Energy Agency, Tokai, Ibaraki 319-1195, Japan
}

(Received November 28, 2009; accepted in revised form October 19, 2010)

\section{EXAFS / U(IV) / Th(IV) / Concentrated electrolyte / Coordination}

Summary. The coordination of $\mathrm{U}^{4+}$ and $\mathrm{Th}^{4+}$ in concentrated $\mathrm{CaCl}_{2}$ solutions is studied by $\mathrm{U}$ and $\mathrm{Th} L_{\mathrm{III}}$ edge extended X-ray absorption fine structure (EXAFS) spectroscopy. With the decrease of concentration of $\mathrm{CaCl}_{2}$ from 6.9 to $4 \mathrm{M}$, the $\mathrm{Cl}^{-}$ion coordination number $N_{\mathrm{Cl}}$ in the $\mathrm{U}^{4+}$ coordination sphere decreases from 3.4 to 1.3 , while the hydration number $N_{\mathrm{O}}$ increases from 4.5 to 6.7 . The combined coordination number $N_{\mathrm{O}}+N_{\mathrm{Cl}}$ of $\mathrm{U}^{4+}$ in concentrated $\mathrm{Cl}^{-}$solution (8.0), is lower than that in $1.5 \mathrm{M}$ perchloric acid aqueous solution (9.0). For $\mathrm{Th}^{4+}$, the decrease of concentration from 6.9 to $4 \mathrm{M} \mathrm{CaCl}_{2}$, the coordination number $N_{\mathrm{Cl}}$ in the $\mathrm{Th}^{4+}$ coordination sphere decreased slightly from 1.9 to 1.5 , while coordination number $N_{\mathrm{O}}$ increased from 7.6 to 8.8 . The $N_{\mathrm{O}}+N_{\mathrm{Cl}}$ of $\mathrm{Th}^{4+}$ in concentrated $\mathrm{Cl}^{-}$solution (9.0), is similar to that in $1.5 \mathrm{M}$ perchloric acid. The bond distance of $\mathrm{U}-\mathrm{Cl}$ $(2.67 \AA)$, is shorter than that of $\mathrm{Th}-\mathrm{Cl}(2.76 \AA)$, because of low coordination number $N_{\mathrm{O}}$ to $\mathrm{U}^{4+}$. By adding $\mathrm{HCl}$ into the system, the $\mathrm{U}^{4+}$ and $\mathrm{Th}^{4+}$ coordination sphere is unchanged. The coordination structures of $\mathrm{U}^{4+}$ and $\mathrm{Th}^{4+}$ in concentrated $\mathrm{LiCl}$ is also discussed.

\section{Introduction}

Highly concentrated aqueous solutions of inorganic electrolytes give a characteristic chemical behavior when compared to their behavior in the water abundant solutions [1]. This is related to the limited amount of water. In order to understand the speciation of $f$-elements in highly concentrated electrolytes, various spectroscopic analyses have been performed [2-11]. They included: electronic absorption spectrometry [2,3]; fluorescence spectrometry [4]; emission lifetime analysis [5,6]; and extended X-ray absorption fine structure, better known as EXAFS analysis [7-11]. According to our EXAFS measurements for $\mathrm{UO}_{2}{ }^{2+}$ in concentrated calcium chloride $\left(\mathrm{CaCl}_{2}\right)$ solution, the coordination number of $\mathrm{Cl}^{-}$in the coordination sphere of $\mathrm{UO}_{2}{ }^{2+}$ decreased

\footnotetext{
*Author for correspondence (E-mail: auehara@rri.kyoto-u.ac.jp).
}

from 2.2 to 1.8 with the increase of water content from 6.9 to $4.7 \mathrm{M} \mathrm{CaCl}_{2}$, while the coordination number of $\mathrm{H}_{2} \mathrm{O}$ increased from 1.4 to 2.1 [3]. The bond distance between uranium and oxygen of the water molecule, $\mathrm{U}-\mathrm{O}_{\mathrm{eq}}$, as determined for $14 \mathrm{M} \mathrm{LiCl}$ was found to be shorter than the value reported for $14 \mathrm{M} \mathrm{LiCl}+0.01 \mathrm{M} \mathrm{HCl}$ [7]. This is because the interaction between $\mathrm{H}^{+}$ions and hydrate water molecule depresses the hydration of $\mathrm{UO}_{2}{ }^{2+}$, and this results in the longer bond distance of $\mathrm{U}-\mathrm{O}_{\mathrm{eq}}$. On the other hand, enough data of $\mathrm{U}^{4+}$ in high concentrated chloride solutions has not been obtained because of the oxidation of $\mathrm{U}^{4+}$ in this environment. Hennig et al. [9] developed an electrochemical cell for insitu EXAFS measurement to prepare $\mathrm{U}^{4+}$ from $\mathrm{UO}_{2}{ }^{2+}$ by the controlled potential electrolysis in concentrated $\mathrm{LiCl}$ solutions. They found that the combined coordination number of $\mathrm{Cl}^{-}$and $\mathrm{H}_{2} \mathrm{O}$ of the $\mathrm{U}^{4+}$ species was 9 at low concentration of $\mathrm{Cl}^{-}$and a smaller coordination number of 8 for $9 \mathrm{M} \mathrm{LiCl}$.

In connection with tetravalent uranium, the coordination sphere of tetravalent thorium also has been studied and compared with that of U(IV) $[12,13]$. Moll et al. [13] determined that the coordination number of $\mathrm{H}_{2} \mathrm{O}$ for both ions is $10.8 \pm$ 0.5 in $1.5 \mathrm{M}$ perchloric acid. The distances in the $\mathrm{U}^{4+}$ and $\mathrm{Th}^{4+}$ coordination sphere are $2.42 \pm 0.01$ and $2.45 \pm 0.01 \AA$, respectively. However, there are few reports which measured or reported the coordination sphere of $\mathrm{Th}^{4+}$ in high concentrated chloride solutions.

In the present study, we studied the coordination spheres of the $\mathrm{U}^{4+}$ and $\mathrm{Th}^{4+}$ in concentrated $\mathrm{CaCl}_{2}$ and $\mathrm{LiCl}$ solution by EXAFS measurement. From the results obtained and the reported data $[3,4]$, we discuss the difference in the coordination environment of U(IV) and Th(IV) complexes for these concentrated media. EXAFS spectra in concentrated chloride ion with and without $\mathrm{H}^{+}$were measured.

\section{Experimental}

\subsection{Sample preparation}

Anhydrous uranium tetrachloride was prepared by the chlorination of $\mathrm{U}_{3} \mathrm{O}_{8}$ with $\mathrm{CCl}_{4}$ at $723 \mathrm{~K}$ [14]. The product was identified by X-ray diffraction spectrometry (XRD) as well 
as by thermal gravimetric and differential thermal analyses (TG-DTA) to be the anhydrous $\mathrm{UCl}_{4}$. Thorium tetrachloride hydrate was prepared by adding hydrochloric acid to thorium nitrate pentahydrate and drying up the solution. This procedure was repeated for three times to completely exchange the nitrate ion of the salt for chloride ion. When $\mathrm{pH}$ was measured after dissolving the product in distilled water, the ratio of mol concentration of $\mathrm{H}^{+}$to that of the product dissolved was negligible. $6.9 \mathrm{M} \mathrm{CaCl}_{2}\left(\mathrm{CaCl}_{2} \cdot 6 \mathrm{H}_{2} \mathrm{O}\right)$ was melted at $323 \mathrm{~K}$, and then the solution was used in the supercooled state at room temperature. The concentration of calcium chloride was adjusted by adding deionized water to $6.9 \mathrm{M} \mathrm{CaCl}_{2}$. Concentrated $\mathrm{LiCl}$ solutions $(14 \mathrm{M})$ were prepared from anhydrous $\mathrm{LiCl}$. The synthesized uranium tetrachloride was dissolved in the concentrated electrolyte solutions. Concentrations of U(IV) and Th(IV) in EXAFS samples were $0.04 \mathrm{M}$ and $0.05 \mathrm{M}$, respectively. As references for EXAFS, two solutions were prepared: (1) a $0.04 \mathrm{M}$ $\mathrm{U}^{4+}$ solution in $1.5 \mathrm{M} \mathrm{HClO}_{4}$ and (2) a $0.05 \mathrm{M} \mathrm{Th}^{4+}$ solution in $1.5 \mathrm{M} \mathrm{HClO}_{4}$. All the chemical reagents were of reagent grade. Two $\mathrm{cm}^{3}$ of each sample were sealed in a thin polyethylene bag which was fabricated for the X-ray measurement. A $5 \mathrm{~mm}$ thick Teflon plate, which has a hole of $8 \mathrm{~mm}$ diameter, was set inside the bag in order to keep the light path to be $5 \mathrm{~mm}$. The sample preparations were carried out in the glove box in an argon atmosphere to avoid the oxidation of the metal ions. When the absorption spectra of these samples were measured after EXAFS experiments, the UV-Vis absorption peak corresponding to U(VI) was not observed. It was confirmed that U(IV) was not oxidized to form $\mathrm{U}(\mathrm{VI})$ since samples were prepared in an argon atmosphere and $\mathrm{U}(\mathrm{IV})$ was highly coordinated by $\mathrm{Cl}^{-}$in concentrated $\mathrm{Cl}^{-}$solutions.

\subsection{EXAFS data acquisition and analysis}

XAFS measurements were carried out in the BL27B beamline [15] of the Photon Factory at the High Energy Accelerator Research Organization (KEK), Japan. Hard X-ray ranging from 5 to $20 \mathrm{keV}$ are available in this beamline with a $\mathrm{Si}(111)$ double-crystal monochromator. Monochromatic X-ray energy was calibrated by using cupper and zirconium metal foil. XAFS measurements were performed based on the $\mathrm{U} L_{\mathrm{III}}$-absorption edge $\left(E_{0}=17.15 \mathrm{keV}\right)$ and Th $L_{\mathrm{III}}$-absorption edge $\left(E_{0}=16.27 \mathrm{keV}\right)$. All solutions were measured in fluorescence mode using a Ge solid state detector at room temperature. The XAFS spectra were analyzed by using WinXAS ver. 3.1 code developed by Ressler [16]. Multiple XAFS scans were collected from each sample at ambient temperature $(298 \mathrm{~K})$, and the results were averaged. The EXAFS data were curve fit using theoretical phase and amplitudes calculated from the program FEFF 8 Rehr et al. [17]. The structures of $\mathrm{UCl}_{4}$ [18] and

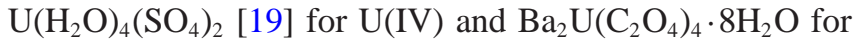
$\mathrm{Th}(\mathrm{IV})$ were used. Due to increasing noise levels at higher $k$-range, data analysis was restricted to the $k$-range $2.5-$ $11.5 \AA^{-1}$ for $\mathrm{U}^{4+}$ and $\mathrm{Th}^{4+}$. The amplitude reduction factor, $\mathrm{S}_{0}^{2}$, was defined as 0.9 in the FEFF calculation and fixed to that value in the data fits. The fitted energy shift parameter, $\Delta E_{0}$, was linked for all shells. Bessel function was used as a window function for the Fourier transforms.

\section{Results}

\section{$3.1 \mathrm{U}^{4+}$ complexes}

Fig. 1a shows the $k^{3}$-weighted EXAFS spectra for $\mathrm{U}^{4+}$ chloride solutions. Fig. $1 \mathrm{~b}$ shows their corresponding Fourier transforms (FTs), along with those for $\mathrm{U}^{4+}$ in $1.5 \mathrm{M} \mathrm{HClO}_{4}$ as a reference, i.e., $0 \mathrm{M} \mathrm{Cl}^{-}$. The perchlorate ion is known to be a noncomplexing ligand for actinide ions because of its weak coordination ability, especially in aqueous solution [20]. Therefore, actinide species in an aqueous perchlorate medium are considered to be pure hydrate complexes. The EXAFS spectrum of $\mathrm{U}^{4+}$ in $1.5 \mathrm{M} \mathrm{HClO}_{4}$ consists of a single oscillation pattern, producing only one FT peak at $R+\Delta=1.92 \AA$, which corresponds to the oxygen atoms of water molecules in the primary coordination sphere of the spherically coordinating $\mathrm{U}^{4+}$. Structural results of the standard EXAFS shell fitting including phase correction are summarized in Table 1. The curve fit results for the spectrum shows that $\mathrm{U}^{4+}$ is surrounded by 9 water molecules at $2.40 \AA$. Recently, the coordination number of water molecules $N_{\mathrm{O}}$ in perchlorate medium is reported to be 9 and 10 as determined by EXAFS $[9,10,13]$. This is larger than the coordination number $N_{\mathrm{O}}$ of 8 as determined by large-angle X-ray scattering [12]. According to the relativistic density functional theory, the coordination number $N_{\mathrm{O}}$ of 9 was predicted [21].

EXAFS oscillation patterns gradually changed with decreasing $\mathrm{Cl}^{-}$concentration from 6.9 to $4 \mathrm{M} \mathrm{CaCl}_{2}$ (sample $\mathrm{U}-\mathrm{C}, \mathrm{U}-\mathrm{D}, \mathrm{U}-\mathrm{E}$ and $\mathrm{U}-\mathrm{F}$ in Table 1), especially in the $k$ range over $9 \AA^{-1}$. Their FTs display a systematic change with decreasing $\mathrm{Cl}^{-}$concentration. The largest peak at $R+$
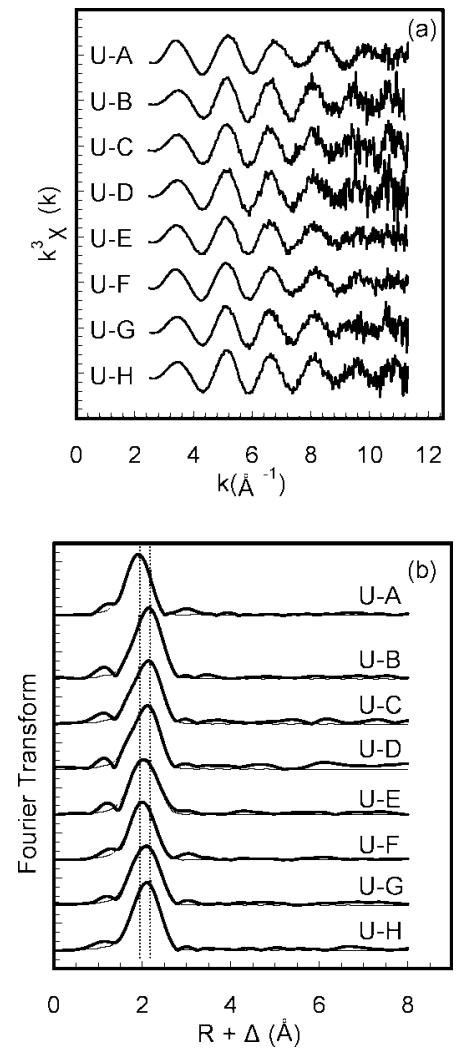

Fig. 1. U $L_{\mathrm{III}}$-edge $k^{3}$-weighted EXAFS data (a) and corresponding Fourier transforms (b) taken over $k=2.5-11.5 \AA^{-1}$ for $\mathrm{U}^{4+}$ as a function of $\mathrm{Cl}^{-}$concentration. 
Table 1. EXAFS structural parameters for $\mathrm{U}^{4+}$ chloride solutions.

\begin{tabular}{|c|c|c|c|c|c|c|c|c|}
\hline & & \multirow{2}{*}{$\begin{array}{c}{\left[\mathrm{Cl}^{-}\right]} \\
\mathrm{mol} \mathrm{kg}^{-1}\end{array}$} & \multicolumn{2}{|c|}{$\mathrm{U}-\mathrm{O}$} & \multicolumn{2}{|c|}{$\mathrm{U}-\mathrm{Cl}$} & \multirow{2}{*}{$N_{\mathrm{O}}+N_{\mathrm{Cl}}$} & \multirow{2}{*}{$\begin{array}{l}\Delta E_{0} \\
(\mathrm{eV})\end{array}$} \\
\hline & & & $N_{\mathrm{O}}$ & $R(\AA)$ & $N_{\mathrm{Cl}}$ & $R(\AA)$ & & \\
\hline $\mathrm{U}-\mathrm{A}$ & $1.5 \mathrm{M} \mathrm{HClO}_{4}$ & 0 & $9.0 \pm 1.4$ & 2.40 & - & - & $9.0 \pm 1.4$ & 7.0 \\
\hline U-B & $14 \mathrm{M} \mathrm{LiCl}$ & 20.2 & $4.2 \pm 0.6$ & 2.42 & $3.7 \pm 0.6$ & 2.68 & $7.9 \pm 0.8$ & 7.4 \\
\hline $\mathrm{U}-\mathrm{C}$ & $6.9 \mathrm{M} \mathrm{CaCl}_{2}$ & 18.5 & $4.5 \pm 0.7$ & 2.40 & $3.4 \pm 0.5$ & 2.67 & $7.9 \pm 0.8$ & 5.9 \\
\hline U-D & $6 \mathrm{M} \mathrm{CaCl}_{2}$ & 15.1 & $4.9 \pm 0.7$ & 2.39 & $3.1 \pm 0.5$ & 2.66 & $8.0 \pm 0.9$ & 5.2 \\
\hline U-E & $5 \mathrm{M} \mathrm{CaCl}_{2}$ & 12.0 & $6.3 \pm 0.9$ & 2.42 & $1.8 \pm 0.3$ & 2.69 & $8.1 \pm 1.0$ & 6.7 \\
\hline U-F & $4 \mathrm{M} \mathrm{CaCl}_{2}$ & 9.24 & $6.7 \pm 1.0$ & 2.43 & $1.3 \pm 0.2$ & 2.66 & $8.0 \pm 1.0$ & 6.1 \\
\hline $\mathrm{U}-\mathrm{G}$ & $6 \mathrm{M} \mathrm{CaCl}_{2}+0.001 \mathrm{M} \mathrm{HCl}$ & 15.1 & $5.5 \pm 0.8$ & 2.41 & $2.5 \pm 0.4$ & 2.68 & $8.0 \pm 0.9$ & 6.5 \\
\hline $\mathrm{U}-\mathrm{H}$ & $6 \mathrm{M} \mathrm{CaCl}_{2}+0.1 \mathrm{M} \mathrm{HCl}$ & 15.3 & $4.9 \pm 0.7$ & 2.41 & $3.2 \pm 0.5$ & 2.66 & $8.1 \pm 0.9$ & 6.2 \\
\hline
\end{tabular}

Errors in distances $R$ are $\pm 0.02 \AA$, errors in coordination numbers $N$ are $\pm 15 \%$. The Debye-Waller factor $\sigma^{2}$ was held constant for the shells $\mathrm{U}-\mathrm{O}, \sigma^{2}=0.009 \AA^{2}$ and $\mathrm{U}-\mathrm{Cl}, \sigma^{2}=0.005 \AA^{2}$, respectively. A $k$ range of $2.5-11.5 \AA^{-1}$ was used.

$\Delta=2.15 \AA$ in $6.9 \mathrm{M} \mathrm{CaCl}_{2}$ shifts to a lower $R$ range, while the largest peak is observed at $R+\Delta=2.00 \AA$ in $4 \mathrm{M} \mathrm{CaCl}_{2}$. As expected from the FTs in Fig. $1 \mathrm{~b}$, systematic changes are found for coordination numbers $N_{\mathrm{O}}$ and $N_{\mathrm{Cl}}$ as a function of $\mathrm{Cl}^{-}$concentration as shown in Table 1 . Here, a Debye-Waller factor $\sigma^{2}$ value of the U-O shell was fixed in the fit to be $0.009 \AA^{2}$ as obtained for the $\mathrm{U}^{4+}$ perchlorate solution, and that of the $\mathrm{U}-\mathrm{Cl}$ shell was fixed to be $0.005 \AA^{2}$ assuming the same value as obtained for $\mathrm{U}(\mathrm{VI})$ [11]. The coordination number $N_{\mathrm{O}}$ increases gradually, while the coordination number $N_{\mathrm{Cl}}$ decreased with decreasing $\mathrm{Cl}^{-}$concentration as shown in Table 1. This indicates that water molecules are replaced by $\mathrm{Cl}^{-}$ion in high $\mathrm{Cl}^{-}$concentration solutions. These results imply that UVVIS-NIR absorption spectra change with $\mathrm{Cl}^{-}$concentration as previously reported [3]. It is noted that the combined coordination number $N_{\mathrm{O}}+N_{\mathrm{Cl}}$ in concentrated $\mathrm{Cl}^{-}$solutions (samples U-B to U-H) was 8, which is lower than that in $1.5 \mathrm{M} \mathrm{HClO}_{4}$ aqueous solution. Decreasing of $N_{\mathrm{O}}+N_{\mathrm{Cl}}$ in $9 \mathrm{M} \mathrm{LiCl}$ was reported by Hennig et al. [9]. This is because the coordination sphere of $\mathrm{U}(\mathrm{IV})$ was occupied by $\mathrm{Cl}$ ion with a larger ionic size. However, the $\mathrm{U}-\mathrm{O}$ and $\mathrm{U}-\mathrm{Cl}$ bond distances are not significantly changing with the $\mathrm{Cl}^{-}$ concentration.

When $14 \mathrm{M} \mathrm{LiCl}$ (sample U-B) was used instead of $\mathrm{CaCl}_{2}$ to compare the effect of cation size on the $\mathrm{U}^{4+}$ coordination, the coordination number $N_{\mathrm{O}}$ decreased and $N_{\mathrm{Cl}}$ increased compared with those in $6.9 \mathrm{M} \mathrm{CaCl}_{2}$ (sample $\mathrm{U}-\mathrm{C}$ ). This suggested that coordination numbers are dependent upon the water activity of $14 \mathrm{M} \mathrm{LiCl}(0.11)$ and $6.9 \mathrm{M} \mathrm{CaCl}_{2}$
(0.19) [22], i.e., coordination number $N_{\mathrm{O}}$ is lower at the solution with lower water activity.

We have reported that the coordination structure of $\mathrm{UO}_{2}{ }^{2+}$ was affected by addition of $\mathrm{H}^{+}$, i.e., the $\mathrm{U}-\mathrm{O}$ bond distance at high $\mathrm{Cl}^{-}$concentration is shortened when $\mathrm{H}^{+}$ ions are added because of interactions between the $\mathrm{H}^{+}$ion and the water molecules of $\mathrm{UO}_{2}{ }^{2+}$ [11]. The effect of $\mathrm{H}^{+}$ion on the coordination of $\mathrm{U}^{4+}$ in high concentration of $\mathrm{Cl}^{-}$was investigated using $6 \mathrm{M} \mathrm{CaCl}_{2}$ with $0.001 \mathrm{M} \mathrm{HCl}$ (sample UG) or $0.1 \mathrm{M} \mathrm{HCl}$ (sample U-H). However, clear differences between sample U-D, U-G and U-H were not observed for the coordination numbers and bond distances.

\section{2 $\mathrm{Th}^{4+}$ complexes}

Fig. 2 shows the $k^{3}$-weighted EXAFS spectra for $\mathrm{Th}^{4+}$ in chloride solutions (a) and their corresponding FTs (b), along with those for $\mathrm{Th}^{4+}$ in $1.5 \mathrm{M} \mathrm{HClO}_{4}$ as a reference. The EXAFS spectrum of $\mathrm{Th}^{4+}$ in $1.5 \mathrm{M} \mathrm{HClO}_{4}$ (sample Th-A) consists of a single oscillation pattern, producing only one FT peak at $R+\Delta=1.92 \AA$ corresponding to the oxygen atoms of water molecules. Structural results of the standard EXAFS shell fitting including phase correction are summarized in Table 2. The curve fit results for the spectrum show that $\mathrm{Th}^{4+}$ is surrounded by 9.6 water molecules at $2.41 \AA$. Our results are less than that estimated by Moll et al. [13] in the same media.

EXAFS oscillation patterns gradually changed with decreasing $\mathrm{Cl}^{-}$concentration from 6.9 to $4 \mathrm{M} \mathrm{CaCl}_{2}$ (samples Th-C, Th-D and Th-E in Table 2). The peak position at $R+$

Table 2. EXAFS structural parameters for $\mathrm{Th}^{4+}$ chloride solutions.

\begin{tabular}{|c|c|c|c|c|c|c|c|c|}
\hline & & \multirow{2}{*}{$\begin{array}{c}{\left[\mathrm{Cl}^{-}\right]} \\
\mathrm{mol} \mathrm{kg}{ }^{-1}\end{array}$} & \multicolumn{2}{|c|}{ Th-O } & \multicolumn{2}{|c|}{$\mathrm{Th}-\mathrm{Cl}$} & \multirow{2}{*}{$N_{\mathrm{O}}+N_{\mathrm{Cl}}$} & \multirow{2}{*}{$\begin{array}{l}\Delta E_{0} \\
(\mathrm{eV})\end{array}$} \\
\hline & & & $N_{\mathrm{O}}$ & $R(\AA)$ & $N_{\mathrm{Cl}}$ & $R(\AA)$ & & \\
\hline Th-A & $1.5 \mathrm{M} \mathrm{HClO}_{4}$ & 0 & $9.6 \pm 1.4$ & 2.41 & - & - & $9.6 \pm 1.4$ & 5.9 \\
\hline Th-B & $14 \mathrm{M} \mathrm{LiCl}$ & 20.2 & $4.7 \pm 0.7$ & 2.42 & $2.7 \pm 0.4$ & 2.76 & $7.4 \pm 0.8$ & 7.4 \\
\hline Th-C & $6.9 \mathrm{M} \mathrm{CaCl}_{2}$ & 18.5 & $7.6 \pm 1.1$ & 2.41 & $1.9 \pm 0.3$ & 2.75 & $9.5 \pm 1.2$ & 9.0 \\
\hline Th-D & $6 \mathrm{M} \mathrm{CaCl}_{2}$ & 15.1 & $7.7 \pm 1.2$ & 2.43 & $2.2 \pm 0.3$ & 2.76 & $9.9 \pm 1.2$ & 8.6 \\
\hline Th-E & $4 \mathrm{M} \mathrm{CaCl}_{2}$ & 9.24 & $8.8 \pm 1.3$ & 2.42 & $1.5 \pm 0.2$ & 2.73 & $10.3 \pm 1.3$ & 7.6 \\
\hline Th-F & $6 \mathrm{M} \mathrm{CaCl}_{2}+0.001 \mathrm{M} \mathrm{HCl}$ & 15.1 & $7.5 \pm 1.1$ & 2.44 & $1.9 \pm 0.3$ & 2.75 & $9.4 \pm 1.2$ & 9.0 \\
\hline Th-G & $6 \mathrm{M} \mathrm{CaCl}_{2}+0.1 \mathrm{M} \mathrm{HCl}$ & 15.3 & $7.8 \pm 1.2$ & 2.44 & $2.0 \pm 0.3$ & 2.75 & $9.8 \pm 1.2$ & 8.9 \\
\hline
\end{tabular}

Errors in distances $R$ are $\pm 0.02 \AA$, errors in coordination numbers $N$ are $\pm 15 \%$. The Debye-Waller factor $\sigma^{2}$ was held constant for the shells Th-O, $\sigma^{2}=0.009 \AA^{2}$ and Th-Cl, $\sigma^{2}=0.005 \AA^{2}$, respectively. A $k$ range of $2.5-11.5 \AA^{-1}$ was used. 

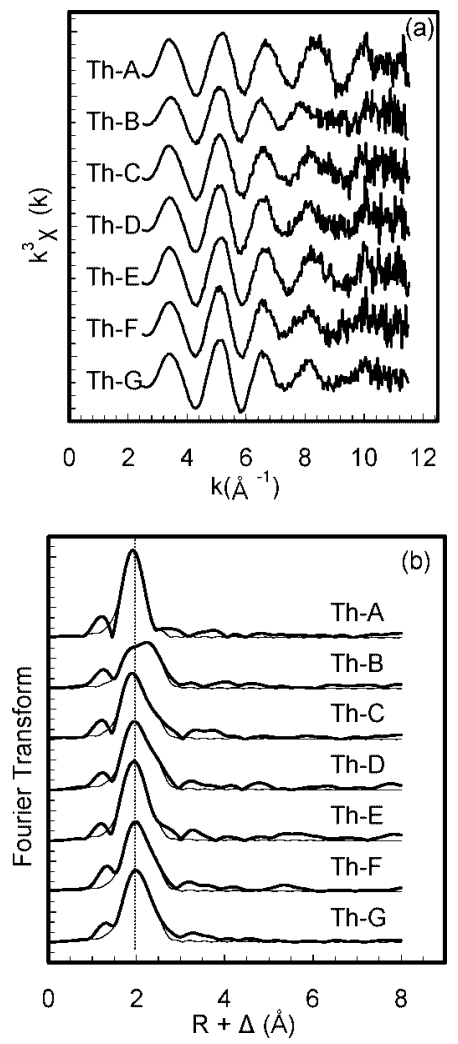

Fig. 2. Th $L_{\mathrm{III}}$-edge $k^{3}$-weighted EXAFS data (a) and corresponding Fourier transforms (b) taken over $k=2.5-11.5 \AA^{-1}$ for $\mathrm{Th}^{4+}$ as a function of $\mathrm{Cl}^{-}$concentration.

$\Delta=1.92 \AA$ is almost independent of $\mathrm{Cl}^{-}$concentration. With the increase of water content from 6.9 to $4 \mathrm{M} \mathrm{CaCl}_{2}$, coordination number $N_{\mathrm{Cl}}$ in the $\mathrm{Th}^{4+}$ coordination sphere slightly decreased from 1.9 to 1.5 , while coordination number $N_{\mathrm{O}}$ increased from 7.6 to 8.8 as shown in Table 2 though $15 \%$ error for each plot was taken into account. Here, a DebyeWaller factor $\sigma^{2}$ value of the Th-O shell was fixed in the fit to $0.007 \AA^{2}$ as obtained for the $\mathrm{Th}^{4+}$ perchlorate solution, and that of the $\mathrm{Th}-\mathrm{Cl}$ shell was fixed to $0.005 \mathrm{~A}^{2}$ assuming the same value for $\mathrm{U}(\mathrm{IV})$. It was also found that the combined coordination number $N_{\mathrm{O}}+N_{\mathrm{Cl}}$ in concentrated $\mathrm{Cl}^{-}$solution was similar to that in $1.5 \mathrm{M} \mathrm{HClO}_{4}$ aqueous solution.

The FT of $14 \mathrm{M} \mathrm{LiCl}$ (sample Th-B) was significantly changed compared with $6.9 \mathrm{M} \mathrm{CaCl}_{2}$ (sample Th-C), a splitting of the FT peak was observed corresponding to well resolved $\mathrm{Th}-\mathrm{O}$ and $\mathrm{Th}-\mathrm{Cl}$ backscattering. The coordination number $N_{\mathrm{O}}$ in sample Th-B was lower and the coordination number $N_{\mathrm{Cl}}$ was higher than that in sample Th-C. It was noted that the combined coordination number $N_{\mathrm{O}}+N_{\mathrm{Cl}}$ in $14 \mathrm{M} \mathrm{LiCl}$ solution was about 8 which is lower than that of $\mathrm{CaCl}_{2}$ series.

The effect of $\mathrm{H}^{+}$ion on the coordination of $\mathrm{Th}^{4+}$ in high concentration of $\mathrm{Cl}^{-}$was investigated using $6 \mathrm{M} \mathrm{CaCl}_{2}$ with $0.001 \mathrm{M} \mathrm{HCl}$ (sample Th-F) or $0.1 \mathrm{M} \mathrm{HCl}$ (sample Th-G). However, clear differences were not observed for the coordination numbers and bond distances.

\section{Discussion}

In perchloric acid solution (samples U-A and Th-A), the coordination number $N_{\mathrm{O}}$ of $\mathrm{U}^{4+}$ is 9.0 , which is smaller than that of $\mathrm{Th}^{4+}$ 9.6. According to the bond valence sum calculation [10], coordination number $N_{\mathrm{O}}<10$ of $\mathrm{U}^{4+}$ is smaller than that of $\mathrm{Th}^{4+}, 10$. Results of the calculation agree with the result obtained in this experiment. On the other hand, coordination number $N_{\mathrm{O}}$ of both $\mathrm{U}^{4+}$ and $\mathrm{Th}^{4+}, 10.8 \pm 0.5$, in similar condition reported by Moll et al. [13] was larger than those obtained in this study. The U-O bond distance, $2.40 \AA$, is similar to the Th-O bond distance, $2.41 \AA$. However, the $\mathrm{U}-\mathrm{O}$ bond distance is about $0.03 \AA$ shorter than $\mathrm{Th}-\mathrm{O}$ bond distance reported by Moll et al. [13].

In concentrated calcium chloride solutions (samples $\mathrm{U}-\mathrm{C}$ to $\mathrm{U}-\mathrm{F}$ and $\mathrm{Th}-\mathrm{C}$ to $\mathrm{Th}-\mathrm{E}$ ), it is noted that the $\mathrm{U}-\mathrm{Cl}$ bond distance, $2.67 \AA$, is significantly shorter than $\mathrm{Th}-\mathrm{Cl}$ bond distance, $2.75 \pm 0.02 \AA$, while the $\mathrm{U}-\mathrm{O}$ bond distance, $2.41 \pm 0.02 \AA$, is similar to the Th-O bond distance, $2.42 \pm$ $0.02 \AA$ A. Fig. 3 shows dependence of coordination numbers $N_{\mathrm{O}}$ and $N_{\mathrm{Cl}}$ for $\mathrm{U}^{4+}$ and $\mathrm{Th}^{4+}$ on the water activity in concentrated $\mathrm{CaCl}_{2}$ and $\mathrm{LiCl}$. The coordination sphere of $\mathrm{U}^{4+}$ is well affected by water activity, i.e., the coordination number $N_{\mathrm{Cl}}$ to $\mathrm{U}^{4+}$ decrease and coordination number $N_{\mathrm{O}}$ increase with increase of water activity. This result indicates that ligands coordinated to $\mathrm{U}^{4+}$ are exchanged from $\mathrm{Cl}^{-}$to $\mathrm{H}_{2} \mathrm{O}$ with increase of water activity. On the other hand, coordination number $N_{\mathrm{Cl}}$ in the $\mathrm{Th}^{4+}$ coordination sphere slightly decreased from 1.9 to 1.5 and coordination number $N_{\mathrm{O}}$ slightly increased from 7.6 to 8.8 with increase of water activity.

These results indicate that the hydration of Th(IV) is stronger than that of U(IV) even in highly concentrated chloride solutions. The combined coordination number $N_{\mathrm{O}}+N_{\mathrm{Cl}}$ of $\mathrm{U}^{4+}$ was determined to be 8 which is obviously lower than those of $\mathrm{Th}^{4+} 9.5$ because of low coordination number
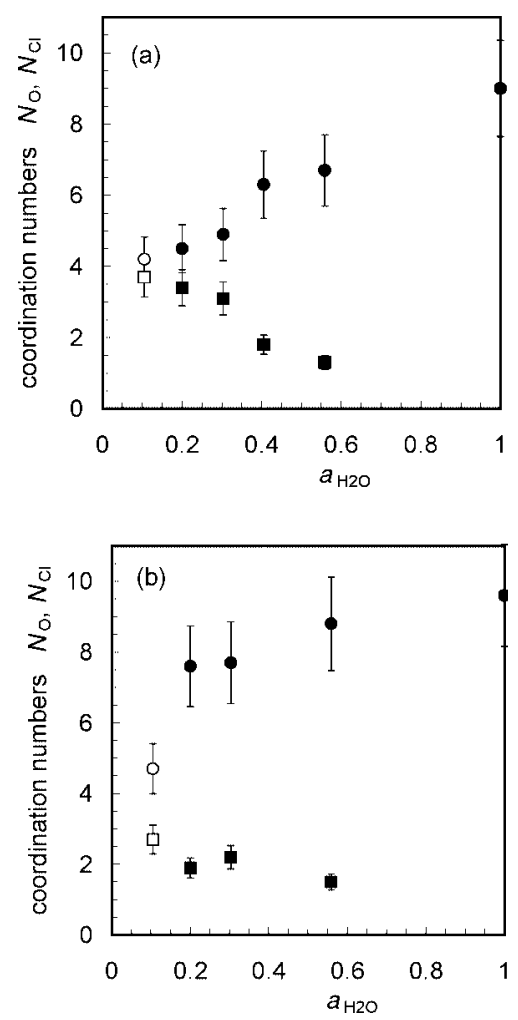

Fig. 3. Dependence of coordination numbers $N_{\mathrm{O}}$ and $N_{\mathrm{Cl}}$ on the water activity $a_{\mathrm{H}_{2} \mathrm{O}}$ in concentrated $\mathrm{CaCl}_{2}$ and LiCl. $\bullet: N_{\mathrm{O}}$ and $\boldsymbol{\square}: N_{\mathrm{Cl}}$ in $\mathrm{CaCl}_{2}, \mathrm{O}: N_{\mathrm{O}}$ and $\square: N_{\mathrm{Cl}}$ in LiCl. (a) is for U(IV), (b) is for Th(IV). Plot of $a_{\mathrm{H}_{2} \mathrm{O}}=1$ shows sample A $\left(1.5 \mathrm{M} \mathrm{HClO}_{4}\right)$. 
$N_{\mathrm{O}}$ of $\mathrm{U}^{4+}$. Since the stability constant of $\mathrm{U}^{4+}-\mathrm{Cl}\left(\log \beta_{1}=\right.$ 2.6) [23] is larger than that of $\mathrm{Th}^{4+}-\mathrm{Cl}\left(\log \beta_{1}=2.0\right)$ [24], the coordination number of $\mathrm{Cl}$ to $\mathrm{U}^{4+}$ should be larger than that to $\mathrm{Th}^{4+}$ in the same concentration of $\mathrm{Cl}$. This trend was observed consistently and with those expected.

It is of interest that coordination number $N_{\mathrm{O}}$ of $\mathrm{Th}^{4+}$ in $\mathrm{LiCl}$ is quite smaller than that estimated from results of $\mathrm{CaCl}_{2}$ systems (Fig. 3b). Hydration of $\mathrm{Th}^{4+}$ might be sensitive to the co-existed cations with strong polarizing power.

The effect of small amount of $\mathrm{H}^{+}$ion on the coordination of $\mathrm{U}^{4+}$ and $\mathrm{Th}^{4+}$ in high $\mathrm{Cl}^{-}$concentration was investigated (samples $\mathrm{U}-\mathrm{D}, \mathrm{U}-\mathrm{G}, \mathrm{U}-\mathrm{H}, \mathrm{Th}-\mathrm{D}, \mathrm{Th}-\mathrm{F}$ and $\mathrm{Th}-\mathrm{G}$ ), however, significant dependences of bond distances and coordination numbers were not observed. This suggests that the $\mathrm{U}^{4+}-\mathrm{OH}_{2}$ and $\mathrm{Th}^{4+}-\mathrm{OH}_{2}$ bond distances were not affected by adding of $\mathrm{H}^{+}$.

Acknowledgment. The above studies have been done under the proposal Nos. 2007G614, 2009G019 and 2009G548 at KEK. The authors thank Prof. K. Kobayashi (KEK), Dr. N. Usami (KEK) and Dr. N. Hirao (JAEA) for their support at the Photon Factory. A part of this study is the result of basic actinide chemistry and physics research in close cooperation with hot laboratories carried out under the Strategic Promotion Program for Basic Nuclear Research by the Ministry of Education, Culture, Sports, Science and Technology of Japan. We thank Mr. Roy Jacobus for his help in improving the English expressions of this paper.

\section{References}

1. Marcus, Y.: Ion Solvation. Wiley, New York (1985), pp. 234-243.

2. McKay, H. A. C., Woodhead, J. K.: A spectrophotometric study of the nitrate complexes of uranium(IV). J. Chem. Soc. 717 (1964).

3. Uehara, A., Fujii, T., Nagai, T., Shirai, O., Sato, N., Yamana, H.: Electrochemical and spectroscopic characteristics of uranium ions in hydrate melt. In: Recent Advances in Actinide Science. (May, I., Alvares, R., Bryan, N., eds.) (2006), pp. 548-550.

4. Fujii, T., Asano, H., Kimura, T., Yamamoto, T., Uehara, A., Yamana, H.: Spectroscopic study of trivalent rare Earth ions in calcium nitrate hydrate melt. J. Alloys Compd. 408, 989 (2006).

5. Kimura, T., Kato, Y.: Luminescence study on the inner-sphere hydration number of lanthanide(III) ions in concentrated aqueous salt solutions in fluid and frozen states. J. Alloys. Compd. 278, 92 (1998).

6. Fanghanel, T., Kim, J. I., Klenze, R., Kato, Y.: Formation of $\mathrm{Cm}$ (III) chloride complexes in $\mathrm{CaCl}_{2}$ solutions. J. Alloys. Compd. 225, 308 (1995).

7. Allen, P. G., Bucher, J. J., Shuh, D. K., Edelstein, N. M., Reich, T.: Investigation of aquo and chloro complexes of $\mathrm{UO}_{2}{ }^{2+}, \mathrm{NpO}_{2}{ }^{+}$, $\mathrm{Np}^{4+}$, and $\mathrm{Pu}^{3+}$ by $\mathrm{X}$-ray absorption fine structure spectroscopy. Inorg. Chem. 36, 4676 (1997).
8. Allen, P. G., Bucher, J. J., Shuh, D. K., Edelstein, N. M., Craig, I.: Coordination chemistry of trivalent lanthanide and actinide ions in dilute and concentrated chloride solutions. Inorg. Chem. 39, 595 (2000).

9. Hennig, C., Tutschku, J., Rossberg, A., Bernhard, G., Scheinost, A. C.: Comparative EXAFS investigation of uranium(VI) and -(IV) аqио chloro complexes in solution using a newly developed spectroelectrochemical cell. Inorg. Chem. 44, 6655 (2005).

10. Ikeda-Ohno, A., Hennig, C., Tsushima, S., Scheinost, A. C., Bernhard, G., Yaita, T.: Speciation and structural study of U(IV) and -(VI) in perchloric and nitric acid solutions. Inorg. Chem. 48, 7201 (2009).

11. Uehara, A., Fujii, T., Matsuura, H., Sato, N., Yamana, H., Okamoto, Y.: EXAFS studies of uranium ions in calcium chloride hydrate melts. OECD-NEA 15, 197 (2009).

12. Johansson, G., Magini, M., Ohtaki, H.: Coordination around thorium(IV) in aqueous perchlorate, chloride and nitrate solutions. J. Sol. Chem. 20, 775 (1991).

13. Moll, H., Denecke, M. A., Jalilehvand, F., Sandstrom, M., Grenthe, I.: Structure of the aqua ions and fluoride complexes of uranium(IV) and thorium(IV) in aqueous solution an EXAFS study. Inorg. Chem. 38, 1795 (1999).

14. Cordfunke, E. H. P.: Chemistry of Uranium. Elsevier (1969), pp. 150-155.

15. Konishi, H., Yokoya, A., Shiwaku, H., Motohashi, H., Makita, T., Kashihara, Y., Hashimoto, S., Haramai, T., Sasaki, T. A., Maeta, H., Ohno, H., Maezawa, H., Asaoka, S., Kanaya, N., Itoh, K., Usami, N., Kobayashi, K.: Synchrotron radiation beamline to study radioactive materials at the photon factory. Nucl. Instrum. Methods Phys. Res. A 372, 322 (1996).

16. Ressler, T.: WinXAS: a program for X-ray absorption spectroscopy data analysis under MS-Windows. J. Synchrotron Radiat. 5, 118 (1998).

17. Ankudinov, A. L., Rehr, J. J.: Relativistic calculations of spindependent X-ray-absorption spectra. Phys. Rev. B 56, R1712 (1997).

18. Schleid, T., Meyer, G.: Facile synthesis of $\mathrm{UCl}_{4}$ and $\mathrm{ThCl}_{4}$, metallothermic reductions of $\mathrm{UCl}_{4}$ with alkali metals and crystal structure refinements of $\mathrm{UCl}_{3}, \mathrm{UCl}_{4}$ and $\mathrm{Cs}_{2} \mathrm{UCl}_{6}$. J. Less-Common. Met. 132, 69 (1987).

19. Kierkegaard, P.: The crystal structure of $\mathrm{U}\left(\mathrm{SO}_{4}\right)_{2} \cdot 4 \mathrm{H}_{2} \mathrm{O}$. Acta Chim. Scan. 10, 599 (1956).

20. Sémon, L., Boehme, C., Billard, I., Hennig, C., Lützenkirchen, K., Reich, T., Roßberg, A., Rossini, I., Wipff, G.: Do perchlorate and triflate anions bind to the uranyl cation in an acidic aqueous medium? A combined EXAFS and quantum mechanical investigation. Chem. Phys. Chem. 2, 591 (2001).

21. Yang, T., Tsushima, S., Suzuki, A.: Chloride concentration and temperature effects on the hydration of Th(IV) ion: a molecular dynamics simulation. Chem. Phys. Lett. 360, 534 (2002).

22. Aseyev, G. G.: Electrolytes Equilibria in Solutions and Phase Equilibria. Begell House Inc., New York (1999).

23. Guillaumont, R., Fanghänel, T., Fuger, J., Grenthe, I., Neck, V., Palmer, D. A., Rand, M. H.: Chem. Thermodyn. 11, 242 (2007).

24. Rand, M., Fuger, J., Neck, V., Grenthe, I., Rai, D.: Chem. Thermodyn. 5, 199 (2003). 